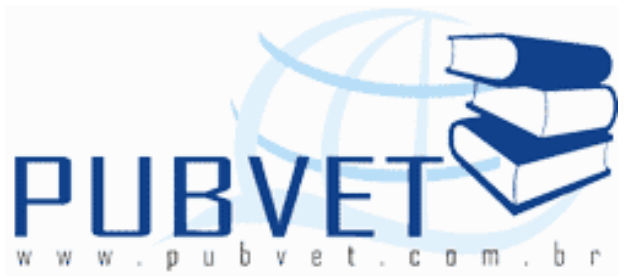

PUBVET, Publicações em Medicina Veterinária e Zootecnia.

\title{
A importância do sistema silvipastoril na pecuária leiteira
}

\section{Paulo Vitor Valentini ${ }^{1}$ e Carlos Renato Tavares de Castro ${ }^{2}$}

${ }^{1}$ Zootecnista, paulovvalentini@yahoo.com.br

${ }^{2}$ Engenheiro Agrônomo, D.Sc. - Pesquisador da Embrapa Gado de Leite - Rua Eugênio do Nascimento, 610 - Bairro Dom Bosco - 36038-330 Juiz de Fora MG, castro@cnpgl.embrapa.br

\section{Resumo}

O estabelecimento de sistemas silvipastoris pode ser uma alternativa viável para promover a sustentabilidade da produção animal a pasto. Esse sistema contribui para conservação do solo e melhoria da sua fertilidade, maior valor nutritivo do pasto, conforto térmico para os animais e maior resgate de $\mathrm{C}$ atmosférico. Além disso, fornece receita extra por meio da comercialização do produto florestal, aspecto relevante para o produtor familiar. Para sucesso desse sistema, a escolha das espécies adequadas é primordial. As forrageiras devem ser tolerantes à sombra e as arbóreas, dispostas em espaçamentos mais amplos, possuir crescimento rápido e copas que proporcionem sombreamento moderado, não tóxico para os animais nem alelopáticas para as pastagens, com potencial econômico. Atividades de pesquisas indicaram maior composição mineral e digestibilidade da forragem e melhor desempenho animal no sistema silvipastoril, comparado a monocultura de algumas espécies avaliadas. Seu potencial de desenvolvimento é indiscutível e seu 
VALENTINI, P.V. e CASTRO, C.R.T. A importância do sistema silvipastoril na pecuária leiteira. PUBVET, Londrina, V. 4, N. 7, Ed. 112, Art. 758, 2010.

reconhecimento tem aumentado nos últimos anos, por meio de pesquisas que vem comprovando diversos benefícios. Contribuindo para que vários pecuaristas adotassem esse sistema.

Palavra-Chave: fertilidade do solo, arborização, degradação da pastagem, valor nutritivo, produção animal.

\section{The importance of silvopastoral system in dairy cattle}

\section{Abstract}

The establishment of silvopastoral systems can be a viable alternative to promote the sustainability of livestock grazing. This system contributes to soil conservation and improvement of its fertility, higher nutritional value of grass, thermal comfort for animals and higher recovery of $C$ air. Furthermore, it provides extra income through marketing of forest products, is relevant for the producer family. For success of this system, the choice of appropriate species is paramount. The forage should be tolerant of shade and trees, arranged in wider spacings, have rapid growth and canopy to provide shade moderate, non-toxic to animals or allelopathic to pasture, with economic potential. Activities of research indicated a greater mineral composition and digestibility of forage and better performance in the silvopastoral system, compared to monoculture of the same species evaluated. Their potential for development is indisputable and recognition has increased in recent years, through research that is showing several benefits. Contributing to several ranchers adopt this system.

Key words: soil fertility, afforestation, degradation of grazing, nutritive value, livestock production.

\section{Introdução}

Os sistemas de produção de bovinos são baseados, principalmente, na utilização de pastagens. Muitas dessas estão associadas à derrubada de 
VALENTINI, P.V. e CASTRO, C.R.T. A importância do sistema silvipastoril na pecuária leiteira. PUBVET, Londrina, V. 4, N. 7, Ed. 112, Art. 758, 2010.

florestas e vegetação nativa, com a eliminação da maioria das árvores existentes, para o estabelecimento de pastagens. Essa técnica acelera o processo de perda de fertilidade do solo e degradação da pastagem quando é observado que a vegetação original não é substituída por sistemas de uso da terra com capacidade para proteção do solo e reposição dos nutrientes, seja pela reciclagem natural ou pela introdução de fertilizantes.

A degradação das pastagens pode ser evidenciada também por meio da escolha equivocada da espécie forrageira, estabelecimento em áreas com declividade acima daquela recomendada; fertilização de estabelecimento deficiente, inadequada correção da acidez do solo; ausência de adubação de manutenção; conhecimento técnico deficiente e, principalmente, falhas no manejo. Associado a este fato tem-se observado deficiências quantitativas e qualitativas da forragem e reduzida eficiência de sua utilização, com impactos negativos sobre a produção animal, resultando em queda dos índices zootécnicos e da rentabilidade econômica do agronegócio.

Uma opção viável para superar problemas de degradação de pastagem e baixo desempenho animal pode ser a utilização de sistemas silvipastoris, que implica na presença de árvores, pastagem e animais na mesma área. Este sistema possui a tentativa de conciliar benefícios ambientais, sociais e econômicos.

Além de vários benefícios para a produção e qualidade da forragem os sistemas silvipastoris melhoram a qualidade do solo e a ciclagem de nutrientes tornando o sistema mais sustentável e fornecendo mais uma forma de renda por meio da extração de produtos florestais, madeira ou lenha.

O presente documento tem como objetivo apresentar fatores importantes no estabelecimento de sistemas silvipastoris. Sua influência em algumas variáveis ambientais, conforto térmico animal, fertilidade do solo, valor nutritivo das forragens cultivadas e desempenho animal. 
VALENTINI, P.V. e CASTRO, C.R.T. A importância do sistema silvipastoril na pecuária leiteira. PUBVET, Londrina, V. 4, N. 7, Ed. 112, Art. 758, 2010.

\section{Sistemas silvipastoris}

Os sistemas silvipastoris são associações de pastagens com cultivos arbóreos e seu objetivo é que árvores, animais e pastagens sejam explorados numa mesma área. Os cultivos arbóreos podem ser compostos por espécies madeireiras, frutíferas e leguminosas.

O estabelecimento desse sistema tem sido uma opção viável para superar os problemas atuais enfrentados, tais como a redução da produção de forragem e redução da fertilidade do solo, comprometendo a produção animal e aumentando os custos de produção e degradação ambiental.

Tais sistemas podem contribuir para minimizar os problemas decorrentes do desmatamento e da degradação de diferentes ecossistemas, possibilitando o melhor aproveitamento dos diferentes estratos vegetais, obtendo diversificação produtiva, do uso da terra, da renda, da mão de obra e da produção de serviços ambientais (Paciullo; Aroeira e Carvalho, 2009).

De acordo com Paciullo et al. (2007), os sistemas silvipastoris também conhecidos como sistemas agroflorestais secundários, podem ser uma forma adequada na busca em aliar produção e conservação ambiental, nos quais deve haver tanto interações ecológicas como econômicas.

Os sistemas silvipastoris são sistemas multifuncionais com possibilidade de intensificar a produção, por meio do manejo integrado dos recursos naturais, evitando sua degradação (Paciullo et al., 2007).

Segundo Paciullo et al. (2007), de maneira geral as principais vantagens desse sistema são: aumento da biodiversidade, fixação de nitrogênio, ciclagem de nutrientes, redução da erosão do solo, proteção de nascentes, melhoria do valor nutricional da forragem para os animais, possibilidade de suplementação alimentar para os animais por meio das folhas de algumas arbóreas ou arbustivas; aumento da retenção de carbono no sistema, melhoria das propriedades químicas e físicas do solo, possibilidade de aumentar oferta de matéria seca, melhor conforto térmico para os animais por meio da sombra 
VALENTINI, P.V. e CASTRO, C.R.T. A importância do sistema silvipastoril na pecuária leiteira. PUBVET, Londrina, V. 4, N. 7, Ed. 112, Art. 758, 2010.

das árvores. Todas essas vantagens resultam em maior produção animal, diversificação de produtos e incremento de renda na propriedade.

Os estudos sobre sistemas silvipastoris têm sido aprofundados nos últimos anos, possibilitando o reconhecimento dos seus benefícios por várias instituições, contribuindo para sua adoção em várias propriedades rurais e por empresas comerciais (Paciullo et al., 2007).

Conforme Oliveira et al. (2003), a maior parte das áreas desmatadas da Amazônia têm sido utilizada para o plantio de culturas anuais e quando diminui a fertilidade do solo, são utilizadas para a pastagem, o que torna a atividade inviável e ecologicamente insustentável, pois resulta na formação de ecossistemas homogêneos com pequena presença de árvores. A atividade pastoril posterior à cultura anual seria viável caso o solo fosse adequadamente manejado. As áreas desmatadas já ultrapassam o limite destinado à reserva legal, é necessário repor a vegetação via reflorestamento, recuperar a fertilidade do solo, aumentar a biodiversidade e regularizar os recursos de água. Nesta situação, os sistemas silvipastoris surgem na região da Amazônia como alternativa de conciliar os sistemas de produção pecuários com as condições ecológicas locais.

Para que o produtor alcance maior nível de sustentabilidade em seu sistema silvipastoril, é necessário conhecer melhor esse sistema, suas vantagens, formas e etapas de implantação, as espécies que podem ser utilizadas, os arranjos e o manejo desse sistema (Oliveira et. al. 2003).

\section{Formas de implantação de sistemas silvipastoris}

Os métodos adotados para a implantação de sistemas silvipastoris dependem da modalidade de sistema, do objetivo do produtor e das condições da área onde será estabelecida. Quando o objetivo principal for produção animal, maiores cuidados deverão ser dispensados às pastagens; caso o objetivo seja produção florestal, maior atenção será dada ao componente 
VALENTINI, P.V. e CASTRO, C.R.T. A importância do sistema silvipastoril na pecuária leiteira. PUBVET, Londrina, V. 4, N. 7, Ed. 112, Art. 758, 2010.

arbóreo (Castro e Paciullo, 2006). No presente documento, o maior foco será a produção animal, em que a densidade do componente arbóreo será menor.

Os principais arranjos encontrados para o sistema silvipastoril são:

Plantio em linhas simples ou duplas: Para o plantio em linha simples pode ser utilizado espaçamento de $5 \times 10 \mathrm{~m}, 10 \times 10 \mathrm{~m}$ ou $5 \times 20 \mathrm{~m}$. Para linha dupla o espaçamento pode ser mais próximo, sugere-se $3 \times 2 \mathrm{~m}$ ou $3 \times 3 \mathrm{~m}$ entre as linhas mais próximas. Entre as linhas duplas, o espaçamento pode ser de 10 a 50 metros, dependendo do objetivo do produtor (Oliveira et. al., 2003). Conforme Paciullo et. al. (2007), quando o relevo for ondulado deve-se plantar árvores em nível, mas se for em sentido plano deve-se dar preferência para o sentido leste-oeste, priorizando a incidência de sol no início da manhã e final da tarde, consequentemente, ocasiona maior crescimento da forragem.

O plantio pode ser planejado para que árvores adultas ocupem cerca de $50 \mathrm{~m}^{2}$ cada, com um arranjo que permite uma cobertura vertical de copas alcançarem 20 a $23 \%$ da área total. Este modelo tem mostrado ser o mais eficiente (Paciullo et al., 2007).

Plantio em bosques: São pequenos aglomerados de árvores, distribuídos na pastagem. Esse sistema ocasiona menor crescimento do pasto dentro do bosque, devido ao excesso de sombra, outra desvantagem é a desuniformidade da ciclagem de nutrientes, já que os animais tendem a concentrar a deposição de fezes e urina dentro dos bosques (Oliveira et al., 2003).

Plantio disperso na pastagem: As árvores são distribuídas aleatoriamente, sem espaçamento definido.

\subsection{Métodos para a implantação das árvores}

O sistema agroflorestal pecuário pode ser formado pelo estabelecimento de pastagens em áreas com remanescentes de vegetação arbórea nativa, pois é recomendada a preservação dessas espécies. Além disso, elas são mais 
VALENTINI, P.V. e CASTRO, C.R.T. A importância do sistema silvipastoril na pecuária leiteira. PUBVET, Londrina, V. 4, N. 7, Ed. 112, Art. 758, 2010.

adaptadas às condições de clima e solo, por isso têm mais chances de sucesso na implantação.

Conforme Oliveira et al. (2003), após o preparo das covas deve ser realizado o plantio das mudas. O torrão deve ser colocado no centro da cova de cinco a 10 centímetros acima do nível do solo, assentando terra e comprimindo bem, para que o colo da muda fique ao mesmo nível do solo, evitando o atraso do desenvolvimento da planta e o aparecimento de fungos.

É imprescindível o controle de formigas cortadeiras, principalmente quando se pretende a introdução de espécies arbóreo-arbustivas exóticas, as quais são mais atacadas por esses insetos. O controle deve ser iniciado pelo menos seis meses antes do plantio, utilizando métodos eficazes, como iscas formicidas, mantendo-o até que as árvores estejam adultas (Castro e Paciullo, 2006).

A adubação das árvores deverá ser realizada diretamente nas covas, em quantidade conforme a interpretação da análise de solo. As mudas, após dois meses, deverão receber adubação de cobertura. As aplicações de corretivos deverão ser realizadas apenas nas faixas cultivadas com distância cerca de um metro, entre elas, aplicados também em quantidades de acordo com a interpretação da analise de solo (Castro e Paciullo, 2006).

Após o plantio das mudas a área deve ser isolada, protegida do gado por meio de cercas, elétrica ou convencional, até que as árvores/arbustos atinjam porte em altura e diâmetro, para não serem mais danificadas pelos animais (Oliveira et al., 2003).

De acordo com Oliveira et al. (2003), podem ser utilizados como medidas para a proteção das mudas, grades de madeira, bambu ou cercas com arame farpado. Outro método que vem sendo desenvolvido no Acre é o plantio próximo aos tocos remanescentes da derrubada de árvores. Este método tem proporcionado menores danos pelos animais. Além disso, acredita-se que é melhor a fertilidade do solo próximo aos tocos, facilitando o crescimento das mudas. 
VALENTINI, P.V. e CASTRO, C.R.T. A importância do sistema silvipastoril na pecuária leiteira. PUBVET, Londrina, V. 4, N. 7, Ed. 112, Art. 758, 2010.

Caso se opte pelo uso da tecnologia de integração lavoura-pecuária, a ausência de pastejo na fase de lavoura evita a necessidade de proteção das mudas (Oliveira et al., 2003).

\section{Considerações sobre a escolha dos componentes do sistema}

\subsection{Escolha da espécie forrageira}

Muitos conceitos devem ser considerados na escolha da espécie forrageira, tais como sua adaptação às condições locais e ao nível tecnológico, o potencial de produção, valor nutritivo da forragem, tolerância ao sombreamento, entre outros.

A escolha de uma espécie forrageira tolerante ou medianamente tolerante ao sombreamento é condição essencial para estabelecer sua associação com árvores (Paciullo et al., 2007).

De acordo com Paciullo et al. (2007), algumas gramíneas tolerantes à sombra moderada, podem manter ou até mesmo aumentar a produtividade em condições de sombreamento moderado e baixo nível de nitrogênio no solo, comparado ao seu desempenho em pleno sol. As gramíneas que apresentaram melhor tolerância foram a Brachiária brizanta, Brachiaria decubens e Panicum maximum; esta última foi a mais tolerante a $30 \%$ de sombreamento atingiu $119,7 \%$ da sua produção a pleno sol. Entre as leguminosas mais tolerantes ao sombreamento destacam-se o Calopogonium mucunoides, a Centrosema pubenses e a Pueraria phaseoloides, o estilosantes (Stylosanthes guianensis) e o Siratro (Macropitlium atropurpureum) foram considerados como de baixa tolerância (Paciullo e Castro, 2009). 
VALENTINI, P.V. e CASTRO, C.R.T. A importância do sistema silvipastoril na pecuária leiteira. PUBVET, Londrina, V. 4, N. 7, Ed. 112, Art. 758, 2010.

\subsection{Componente arbóreo}

Para associar árvores com pastagens alguns aspectos devem ser considerados na escolha do componente arbóreo, devendo ser priorizadas características como crescimento rápido; facilidade de estabelecimento; adaptação ao ambiente e tolerância à seca, geada ou encharcamento do solo; capacidade para fornecer nitrogênio e outros nutrientes à pastagem; potencial para fornecer forragem palatável; tolerância ao ataque de insetos e doenças; ausência de efeitos alelopáticos sobre as plantas associadas; capacidade de fornecer sombra e abrigo para os animais; possuir o potencial para o controle da erosão devendo ter raízes profundas, resistência ao vento e sem caráter invasor (Paciullo; Aroeira e Carvalho, 2009).

Segundo Paciullo et al. (2007), aconselha-se optar por árvores que promovam um sombreamento apenas moderado, permitindo que parte da radiação solar atravesse sua copa, uma vez que mesmo gramíneas medianamente tolerantes ao sombreamento tiveram redução acentuada na produção de forragem quando submetidas a sombreamentos superiores a $50 \%$ da luz solar plena.

Castro e Paciullo (2006) comentam que as espécies leguminosas possuem maior importância para o enriquecimento do solo pela fixação de nitrogênio adicionando maior quantidade de biomassa ao solo da pastagem. Sempre que possível, deve-se preferir as nativas, pois estão adaptadas às condições adafoclimáticas e a pressão biótica local. De acordo com as espécies que já foram estudadas na Embrapa Gado de Leite, destacam-se o angico mirim (Mimosa artemisiana), angico vermelho (Anadenanthera macrocarpa), angico branco (Anadenanthera colubrica), jacarandá da Baía (Dalbergia nigra) e jacaré (Piplatadenia). Dentre elas, o angico mirim foi a que mais se destacou por apresentar crescimento rápido e alta capacidade para adicionar nutrientes a pastagem de gramínea. 
VALENTINI, P.V. e CASTRO, C.R.T. A importância do sistema silvipastoril na pecuária leiteira. PUBVET, Londrina, V. 4, N. 7, Ed. 112, Art. 758, 2010.

Na região amazônica espécies como o cedro, bordão velho, freijó, algodoeiro, sumáuna, piranheira, faveira, capoeiro, eucalipto, teca, mogno, marupá, ingá e mulateiro apresentam boa adaptação a sistemas silvipastoris por suas mudas serem mais resistentes e as plantas adultas serem menos exigentes em fertilidade do solo (Oliveira et al., 2003).

\section{Benefícios ambientais do sistema silvipastoril}

Os principais benefícios ambientais são a amenização da temperatura, redução das perdas de umidade do solo e redução das taxas de evapotranspiração, em decorrência da menor temperatura ambiente. 0 componente arbóreo-arbustivo contribui para regular a temperatura do ar, diminuindo sua variação ao longo do dia, proporcionando benefícios aos animais e plantas que integram o sistema (Paciullo; Aroeira e Carvalho, 2009). Conforme Oliveira et al. (2003), a sombra proporcionada pelas árvores é uma das mais eficientes formas de conferir conforto térmico ao gado leiteiro criado a pasto e sua falta pode causar queda de 10 a $20 \%$ na produção de leite.

A presença organizada de árvores atua como quebra ventos, reduzindo a velocidade dos ventos e atenuando seu efeito dessecativo sobre as plantas e o solo (Paciullo; Aroeira e Carvalho, 2009).

Alguns organismos internacionais têm se empenhado na tentativa de incentivar sistemas de produção que possam contribuir para melhorias ambientais. Os sistemas silvipastoris são uma forma de prestação de serviços ambientais, desde que estejam de acordo com as premissas dos MDL (mecanismo de desenvolvimento limpo). Os seus principais benefícios, aceitos mundialmente como serviços ambientais são a proteção da água em quantidade e qualidade, conservação e melhoria da biodiversidade, o embelezamento paisagístico (eco e agroturismo) e mitigação dos gases de efeito estufa principalmente dióxido de carbono $\left(\mathrm{CO}_{2}\right)$ metano $(\mathrm{CH} 4)$ e óxido nitroso $\left(\mathrm{N}_{2} \mathrm{O}\right)$ (Paciullo et al., 2007). 
VALENTINI, P.V. e CASTRO, C.R.T. A importância do sistema silvipastoril na pecuária leiteira. PUBVET, Londrina, V. 4, N. 7, Ed. 112, Art. 758, 2010.

De acordo com Paciullo, Aroeira e Carvalho (2009), além da fixação de carbono na gramínea ou na leguminosa herbácea, existe também acúmulo na madeira e nas raízes das árvores. Por meio da maior captação de luz, os sistemas silvipastoris conferem maior produtividade primária líquida que indica maior imobilização de carbono no sistema. De acordo com a tabela 1, observase maior conteúdo de carbono no solo quando se combinou pastagens de gramíneas com planta arbórea Leucena leucoplasia e Prosopis Juliflora.

Tabela 1- Conteúdo de carbono no solo (\%) de dois sistemas silvipastoris versus monocultura de gramíneas.

\begin{tabular}{|c|l|l|l|}
\hline \multirow{2}{*}{ Sistema } & \multicolumn{3}{|c|}{ Profundidade } \\
\cline { 2 - 4 } & $0-10 \mathrm{~cm}$ & $10-20 \mathrm{~cm}$ & $20-30 \mathrm{~cm}$ \\
\hline $\begin{array}{c}\text { C. plectostachyus + P. } \\
\text { juliflora + Leucena }\end{array}$ & 1,69 & 1,40 & 0,93 \\
\hline $\begin{array}{c}\text { C. plectostachyus + P. } \\
\text { juliflora }\end{array}$ & 1,49 & 1,19 & 0,65 \\
\hline C. plectostachyus. & 1,00 & 0,70 & 1,48 \\
\hline
\end{tabular}

Fonte Paciullo e Castro (2009)

\section{Benefícios do sistema silvipastoril para o solo}

Maiores benefícios para o solo têm sido observados com a presença do componente arbóreo, especificamente as leguminosas, pois essas influenciam na quantidade e na disponibilidade de nitrogênio na zona de atuação do seu sistema radicular a partir da fixação biológica de $\mathrm{N}_{2}$. As árvores reduzem as perdas de nutrientes causados por diversos processos, como lixiviação, erosão, e aumentam a disponibilidade de nutrientes pela sua maior deposição e posterior decomposição da matéria orgânica do solo (Paciullo e Castro, 2009).

Conforme Paciullo et. al (2009), as raízes profundas das árvores podem interceptar nutrientes que são lixiviados das camadas superficiais e se acumulam no subsolo geralmente fora do alcance do sistema radicular das forrageiras herbáceas, retornando-os à superfície e consequentemente 
VALENTINI, P.V. e CASTRO, C.R.T. A importância do sistema silvipastoril na pecuária leiteira. PUBVET, Londrina, V. 4, N. 7, Ed. 112, Art. 758, 2010.

disponibilizando-as para as forrageiras. Ribaski; Rakocevic e Ribaski (2002) comentam que o sistema radicular das árvores possibilita recuperar nutrientes abaixo do sistema radicular das pastagens diminuindo suas perdas por lixiviação e erosão, aumentando a disponibilidade desses nutrientes pela sua maior liberação na matéria orgânica do solo (ciclagem de nutrientes), além de contribuir para a fixação de carbono.

O sombreamento também tem promovido significativas alterações na qualidade do solo. Segundo Paciullo et al. (2008), a sombra reduz a temperatura do solo entre 5 e $10^{\circ} \mathrm{C}$, a dependendo sua movimentação durante o dia. Esse efeito é importante no aumento do crescimento das plantas, tanto pela redução do déficit hídrico, quanto pelo favorecimento da atividade microbiana na serrapilheira e no solo.

Segundo Paciullo e Castro (2009) a sombra produzida pelas árvores é um dos fatores responsáveis pelo aumento da disponibilidade de nitrogênio no solo, uma vez que há evidencias que a taxa de mineralização é estimulada pela melhoria das condições de temperatura e umidade decorrentes do sombreamento. A melhoria do ambiente do solo sob a copa das árvores possibilita atividade microbiana mais efetiva na decomposição da matéria orgânica, o que resulta em maior liberação do nitrogênio mineralizado.

Conforme Paciullo e Castro (2009), com a presença de leguminosas a dinâmica e a velocidade do processo de decomposição tornam-se mais eficientes, uma vez que a relação carbono/nitrogênio $(C / N)$ desse material é baixa, favorecendo a maior atividade dos microorganismos, acelerando o processo de decomposição e mineralização dos principais nutrientes do ecossistema.

Sistemas silvipastoris têm proporcionado efeitos positivos e disponibilidade de nutrientes para as plantas o que também contribui para aumentar a persistência das pastagens. Paciullo e Castro (2009) observaram aumentos nos teores de cálcio, magnésio, fósforo e potássio em amostras de solo coletadas sob copa de árvores leguminosas em relação àquelas coletadas em áreas de pastagem sem árvores. 
VALENTINI, P.V. e CASTRO, C.R.T. A importância do sistema silvipastoril na pecuária leiteira. PUBVET, Londrina, V. 4, N. 7, Ed. 112, Art. 758, 2010.

A presença do componente arbóreo repercute sobre o balanço hídrico do solo, contribuindo para a manutenção da umidade disponível para as plantas sob a área de influência das copas das árvores. Após a chuva, o teor de umidade do solo se reduz mais lentamente à sombra do que em condições de sol pleno, pois a sombra de árvores, ao reduzir a temperatura do solo diminuem a taxa de evapotranspiração. Essa mudança é importante na redução do déficit hídrico, principalmente em regiões de temperaturas mais elevadas. A manutenção de níveis mais adequados de umidade no solo por um maior período de tempo contribui para o crescimento das gramíneas, também favorecendo a atividade microbiana na serrapilheira e no solo. Com a diminuição do conteúdo de água no solo a atividade microbiana e a mineralização do nitrogênio decrescem, isto ocorre porque os microorganismos do solo se concentram na película de água localizada entre suas partículas, assim sendo a densidade microbiana depende diretamente da umidade do solo (Paciullo e Castro, 2009).

As árvores podem contribuir para o controle da erosão eólica e hídrica por meio da sua ação como quebra-ventos que reduz a dessecação da cobertura vegetal do solo, diminuindo as perdas indiretas de água no sistema e reduz a evaporação da umidade do solo. A erosão hídrica é amenizada pela redução decorrente da sua intensidade pelas folhas e galhos e do amortecimento do impacto pela manta orgânica, aumento da infiltração de água no solo e contribuindo para reduzir o escorrimento (Paciullo e Castro, 2009).

\section{Produção de forragem em sistemas silvipastoris}

A produção de forragem e seu crescimento em associação com árvores pode ser prejudicado ou favorecido, dependendo de fatores como a tolerância à sombra e a competição entre as plantas pela água e nutrientes do solo (Paciullo e Castro, 2009). 
VALENTINI, P.V. e CASTRO, C.R.T. A importância do sistema silvipastoril na pecuária leiteira. PUBVET, Londrina, V. 4, N. 7, Ed. 112, Art. 758, 2010.

A produção de matéria seca das gramíneas forrageiras estabelecidas em sub-bosque é afetada de modo diferente pelas condições ambientais prevalecentes, advindas da competição com a espécie arbórea. Alguns resultados conduzidos no Centro Nacional de Pesquisa Gado de Leite (CNPGL) revelaram que a $B$. decumbens se mostrou pouco tolerante ao sombreamento intenso (65\% de sombreamento em relação à condição de sol pleno), a diminuição do sombreamento de 65 para 35\% resultou em aumentos da ordem de $65 \%$ para a massa de forragem evidenciando a tolerância dessa espécie ao sombreamento moderado. Sob sombreamento artificial de $60 \%$ foi observado redução de $50 \%$ no rendimento forrageiro dessa espécie. A tabela 2 demonstra o efeito do sombreamento no desenvolvimento da $B$. decumbens.

Tabela 2- Massa de forragem ( $\mathrm{Kg} / \mathrm{ha}$ de $\mathrm{MS}$ ) em pastagens de $\mathrm{B}$. decumbens em condições de sombreamento por árvores ou a sol pleno

\begin{tabular}{|l|l|l|}
\hline & Sol pleno & Sombreamento \\
\hline $1^{\circ}$ ano - sombra de $65 \%$ & 1.501 & 698 \\
\hline $2^{\circ}$ ano - sombra de 35\% & 1.260 & 1.158 \\
\hline
\end{tabular}

Paciullo e Castro 2009

A espécie Brachiaria brizantha cv. Marandu apresentou comportamento semelhante, havendo redução de $60 \%$ na sua taxa de acúmulo de MS quando cultivada sob $70 \%$ sombreamento artificial.

Sartor et al. (2004) avaliaram o desempenho de diversas forragens hibernais em um sistema silvipastoril no município de Abelardo Luz - SC, numa área de Pinnus taeda. Comparando três níveis de sombreamento: céu aberto e dentro do bosque com duas densidades de árvores, sendo $9 \mathrm{~m}$ o espaçamento entre linhas e $3 \mathrm{~m}$ na linha e $15 \mathrm{~m}$ entre linhas e $3 \mathrm{~m}$ na linha. Verificou-se que o azevém foi à espécie mais adaptada às condições impostas podendo ser utilizado em sistemas silvipastoril, enquanto as outras espécies testadas demonstram não ser adaptadas ao sombreamento, nas condições 
VALENTINI, P.V. e CASTRO, C.R.T. A importância do sistema silvipastoril na pecuária leiteira. PUBVET, Londrina, V. 4, N. 7, Ed. 112, Art. 758, 2010.

edafoclimáticas do local do experimento. Os valores são apresentados de acordo com a tabela 3.

Tabela 3- Produção de forragem, (Kg, MS/ha) de cinco espécies submetidas a diferentes níveis de sombreamento durante um período de seis meses.

\begin{tabular}{|l|l|l|l|l|} 
Espécie & Céu aberto & $9 \times 3$ & $15 \times 3$ & Média \\
\hline Aveia preta & $4115 \mathrm{ef}$ & $1401 \mathrm{i}$ & $1992 \mathrm{hi}$ & 2503 \\
\hline Aveia branca & $6392 \mathrm{bc}$ & $1694 \mathrm{~h} 1$ & $3324 \mathrm{fg}$ & 3803 \\
\hline Azevém & $6827 \mathrm{~b}$ & $4425 \mathrm{def}$ & $5440 \mathrm{~cd}$ & 5564 \\
\hline Trevo branco & $4706 \mathrm{de}$ & $1273 \mathrm{i}$ & $1305 \mathrm{i}$ & 2428 \\
\hline Cornichão & $8121 \mathrm{a}$ & $2669 \mathrm{gh}$ & $2844 \mathrm{gh}$ & 4543 \\
\hline
\end{tabular}

Médias seguidas de mesma letra, não diferem significativamente, entre si, pelo Teste DMS a 5\%. Sartor et al. (2004)

Outro experimento avaliando espécies hibernais foram conduzidos por Barro et al. (2008), a qual Avaliou-se o efeito do sombreamento provocado por duas densidades arbóreas (555 e 333 árvores/ha) e luz solar plena em uma floresta de Pinus elliottii, no Rio grande do Sul, utilizando três espécies forrageiras, azevém-anual (Lolium multiflorum Lam.); aveia-preta (Avena strigosa Schreb.); e aveia-branca (A. sativa L.) CV. Foi constatato que o sombreamento moderado reduziu em $57 \%$ o rendimento médio de forragem dos três genótipos avaliados. Sendo que, a aveia-branca e aveia-preta apresentam rendimentos de forragem superiores aos do azevém-anual.

Analisando a morfologia das forragens de sistemas silvipastoril foi observado que com aumento do sombreamento em gramíneas tropicas resultou em lâminas foliares e colmos mais longos e folhas de menor espessura, isso ocorreu devido às maiores taxas de alongamento de folhas e colmos quando submetidas à luminosidade reduzidas em condições de sombreamento por árvores ou sol pleno. Em clima temperado tem observado aumentos da área foliar específica com a diminuição da luminosidade (Paciullo e Castro, 2009). 
VALENTINI, P.V. e CASTRO, C.R.T. A importância do sistema silvipastoril na pecuária leiteira. PUBVET, Londrina, V. 4, N. 7, Ed. 112, Art. 758, 2010.

Avaliando o perfilhamento foi constatada redução de sua taxa em gramíneas quando submetidas ao sombreamento. Uma explicação para este fato é a alteração da qualidade da luz que passa através das copas das árvores, suas folhas absorvem preferencialmente luz da faixa 400-700nm. A radiação correspondente ao comprimento de onda do azul e do vermelho é reduzida em comparação com a radiação verde e infravermelha. A redução dessa relação, em condições de sombreamento natural, apresenta importantes efeitos sobre a morfogênese das plantas, principalmente pela diminuição do perfilhamento das gramíneas (Paciullo e Castro, 2009). Outras alterações morfológicas observadas foram à maior relação parte aérea:raiz e maior proporção de folhas verdes com aumento do sombreamento (Paciullo e Castro, 2009).

Castro; Carvalho e Freitas (2001) avaliaram três níveis de sombreamento artificial (0, 30 e 60\%) sobre a composição mineral de seis espécies de gramíneas forrageiras tropicais (Andropogon gayanus, Brachiaria brizantha, $B$. decumbens, Melinis minutiflora, Panicum maximum e Setaria sphacelata). Foi realizado delineamento com blocos ao acaso e nas parcelas foram distribuídos os níveis de sombreamento e nas subparcelas, as espécies forrageiras. Constataram que, com o sombreamento, houve tendência geral à elevação dos teores de fósforo, potássio, cálcio e magnésio na forragem.

Paciullo e Castro (2009) verificaram também que nas lâminas foliares o teor de PB foi $29 \%$ maior à sombra do que no sol, pois a sombra possibilita maior retenção de água no solo, cujo efeito positivo sobre a atividade microbiana resulta em uma maior ciclagem de nutrientes e decomposição da matéria orgânica. À sombra, as gramíneas apresentaram um ligeiro aumento da digestibilidade (1 a 3\%), em virtude de sua forragem possuir menor concentração de parede celular. Observou-se menor concentração de FDN à sombra devido à maior disponibilidade de fotoassimilados ao sol, o que resulta em aumento na quantidade de tecido esclerenquimático, com maior número de células e paredes celulares mais espessas. Segundo Pacillo e Castro (2009), outra possível explicação para maior digestibilidade das forragens se deve as 
VALENTINI, P.V. e CASTRO, C.R.T. A importância do sistema silvipastoril na pecuária leiteira. PUBVET, Londrina, V. 4, N. 7, Ed. 112, Art. 758, 2010.

suas células estarem mais esparsamente arranjadas no mesófilo foliar e com maior quantidade de espaços intercelulares em condições de sombreamento quando comparado a pleno sol. A tabela 4 avalia o efeito do sombreamento na digestibilidade e teor de fibra da $B$. decumbens.

Tabela 4- Teores de fibra em detergente neutro (FDN) e digestibilidade in vitro da MS (DIVMS) da Brachiaria decumbens em condições de sol pleno ou sombreamento por árvores.

\begin{tabular}{|l|l|l|l|}
\hline \multirow{2}{*}{ Característica } & \multicolumn{2}{|l|}{ Tratamento } & \multirow{2}{*}{ Significância } \\
\cline { 2 - 4 } & Sol pleno & Sombreado & \\
\hline FDN (\%) & 75,9 & 73,1 & $*$ \\
\hline DIVMS (\%) & 47,6 & 53,2 & $* *$ \\
\hline
\end{tabular}

Fonte: Paciullo e Castro 2009

Conforme Castro e Carvalho (2000) o sucesso de um sistema silvipastoril depende, dentre outros fatores, da persistência do componente forrageiro do seu sub-bosque, e a autoperpetuação, nas pastagens, que depende essencialmente da quantidade de sementes viáveis produzidas e da intensidade de florescimento.

Castro e Carvalho (2000) realizaram, no CNPGL localizado na Zona da Mata de Minas Gerais, observações relativas ao florescimento de seis espécies de gramíneas forrageiras tropicais (Brachiaria brizantha cv. Marandú; Brachiaria decumbens; Melinis minutiflora; Andropogon gayanus cv. Planaltina; Panicum maximum cv. Vencedor; Setaria sphacelata cv. Kazungula), cultivadas sob condições de luminosidade reduzida. Os resultados indicam efeito negativo do sombreamento sobre a floração da maioria das espécies estudadas. Esse resultado pode ser explicado devido à baixa intensidade de radiação ambiente limitar o suprimento de alguns metabólitos essenciais requeridos para o crescimento dessas estruturas reprodutivas.

Castro et al. (2008) conduziram outro experimento no CNPGL, a qual foi observado menores taxas de natalidade de perfilhos da $B$. decumbens quando 
VALENTINI, P.V. e CASTRO, C.R.T. A importância do sistema silvipastoril na pecuária leiteira. PUBVET, Londrina, V. 4, N. 7, Ed. 112, Art. 758, 2010.

sombreadas por árvores, esses resultados podem ser compensadas pelas menores taxas de mortalidade no sistema sombreado, proporcionando densidade populacional de perfilhos próxima, embora estatisticamente diferentes, daquela observada em áreas não sombreadas. Castro e Garcia (1996) observaram redução do perfilhamento do Panicum maximum cv. Trichoglume com o sombreamento, porém os perfilhos formados apresentaram maior altura comparada àqueles produzidos a plena luz.

\section{Produção animal em sistemas silvipastoris}

Paciullo e Castro (2006) avaliando a massa e composição química da forragem, sua digestibilidade in vitro da matéria seca e o consumo e ganho de peso de novilhas Holandês x Zebu realizadas no período de março/2003 a março/2004, em dois sistemas de recria: sistema silvipastoril e pastagem exclusiva de $B$. decumbens no CNPGL. Os valores de massa de forragem e sua composição química, consumo de matéria seca e ganho de peso diário por novilhas mestiças não diferiram entre os dois sistemas. Foi possível obter ganhos de peso com novilhas Holandês $x$ Zebu de aproximadamente de 300 $\mathrm{g} /$ novilha/dia durante a seca e $600 \mathrm{~g} /$ novilha/dia durante as chuvas. Apesar da igualdade no desempenho zootécnico dos sistemas, o sistema silvipastoril possibilitou a produção de madeira, resultando em vantagem para o produtor rural por meio da possibilidade de obtenção de renda adicional à produção pecuária. As tabelas 5 e 6 comparam o ganho de peso e o consumo de novilhas respectivamente, conforme os resultados desse experimento. 
VALENTINI, P.V. e CASTRO, C.R.T. A importância do sistema silvipastoril na pecuária leiteira. PUBVET, Londrina, V. 4, N. 7, Ed. 112, Art. 758, 2010.

Tabela 5- Ganho de peso (g/novilha/dia) de novilhas leiteiras, de acordo com a época do ano e o sistema de recria.

\begin{tabular}{|l|l|l|}
\hline \multirow{2}{*}{ Sistema de recria } & \multicolumn{2}{|l|}{ Época do ano } \\
\cline { 2 - 3 } & Seca & Chuvas \\
\hline Sistema silvipastoril & 304 & 637 \\
\hline $\begin{array}{l}\text { Pastagem de Braquiaria } \\
\text { exclusiva }\end{array}$ & 313 & 612 \\
\hline Média & $309 \mathrm{~b}$ & $625 \mathrm{a}$ \\
\hline
\end{tabular}

Médias seguidas de letras diferentes, diferem a $5 \%$ pelo teste $\mathrm{F}$.

Fonte: Castro e Paciullo (2006).

Tabela 6- Estimativa do consumo de MS (\% do peso vivo) por novilhas leiteiras, em diferentes épocas do ano, em dois sistemas de recria (Sistema silvipastoril e Brachiária decumbens em monocultura).

\begin{tabular}{|l|l|l|l|l|}
\hline \multicolumn{2}{|c|}{$\begin{array}{l}\text { Época do ano } \\
\text { Sistema de recria }\end{array}$} & \multicolumn{2}{|l|}{ Seca } & \multicolumn{2}{l|}{ Chuvas } \\
\cline { 2 - 5 } & $\begin{array}{l}\text { Mar.- } \\
\text { maio/03 }\end{array}$ & $\begin{array}{l}\text { Jul.- } \\
\text { set./03 }\end{array}$ & $\begin{array}{l}\text { Out.- } \\
\text { dez./03 }\end{array}$ & Mar./04 \\
\hline Sistema silvipastoril & 2,38 & 1,63 & 2,15 & 2,60 \\
\hline Bd Monocultura & 2,31 & 1,57 & 2,13 & 2,43 \\
\hline Média & $2,35 a$ & $1,60 \mathrm{~b}$ & $2,14 \mathrm{a}$ & 2,52 a \\
\hline
\end{tabular}

Médias seguidas de letras diferentes, diferem a $5 \%$ pelo teste $\mathrm{F}$.

Fonte: Castro e Paciullo (2006)

Outros estudos conduzidos no CNPGL observaram que o uso de sistemas silvipastoris na recria de novilhas leiteiras pode ser vantajoso, por permitir bom desempenho das novilhas a um baixo custo de manutenção. Além disso, o silvipastoril se mostrou mais eficiente do que uma pastagem de $B$. decumbens solteira, tendo em vista os maiores ganhos de peso vivo obtidos na pastagem arborizada, durante a época chuvosa (Paciullo et al., 2009). 
VALENTINI, P.V. e CASTRO, C.R.T. A importância do sistema silvipastoril na pecuária leiteira. PUBVET, Londrina, V. 4, N. 7, Ed. 112, Art. 758, 2010.

A avaliação da produção animal em sistemas silvipastoris ainda são escassos revisões de literatura, especialmente sobre a produção de leite.

Um estudo conduzido na região sudeste da Austrália constatou que após oito semanas de pastejo, a produção média de leite aumentou em 1,45L/vaca/dia de vacas holandesas em pastagens consorciadas em animais que tinham acesso à sombra (Silver, 1987 citador por Paciullo e Castro, 2009).

Outros resultados observaram que em um sistema silvipastoril na Colômbia obteve incrementos da produção de leite, de 10.585 para 12.702L/ha/ano, entre outros benefícios demonstrados na tabela 7 (Murgueitio, 2000 citado por Paciullo e Castro, 2009).

Tabela 7- Indicadores técnicos e ambientais de um sistema silvipastoril (Cynodon plectostachyus + Leucaena leucocephala + Prosopis juliflora) x pastagem de capim estrela.

\begin{tabular}{l|l|l|}
\hline Indicadores & $\begin{array}{l}\text { Capim-estrela } \\
+\mathrm{N}\end{array}$ & $\begin{array}{l}\text { Sistema } \\
\text { silvipastoril }\end{array}$ \\
\hline Taxa de lotação, vacas/ha & 4,0 & 4,8 \\
\hline Produção de leite, kg/vaca/dia & 9,5 & 9,5 \\
\hline Produção de leite, kg/ha & 10.585 & 12.702 \\
\hline Adubação (uréia), kg/ha & 400 & 0 \\
\hline Água consumida, m³/ha/ano & 16.000 & 12.000 \\
\hline M. orgânica do solo (0-10cm), \% & 1,6 & 2,8 \\
\hline
\end{tabular}

Fonte: Murgueitio (2000) adaptado por Pacciulo e castro (2009)

\section{Conclusões}

Seu potencial de desenvolvimento no Brasil é indiscutível, frente a todos os seus benefícios ambientais sociais e econômicos. Maior número de pesquisadores tem dedicado seus trabalhos a esse sistema, o que tem contribuído para obtenção de novos conhecimentos e a consolidação dessa 
VALENTINI, P.V. e CASTRO, C.R.T. A importância do sistema silvipastoril na pecuária leiteira. PUBVET, Londrina, V. 4, N. 7, Ed. 112, Art. 758, 2010.

linha de pesquisa no país. Os sistemas silvipastoris surgem como alternativa promissora futura por ter se apresentado mais diversificados e sustentáveis.

\section{Referências bibliográficas}

BARRO, R.S.; SAIBRO, J.C.; MEDEIROS, R.B. et al. Rendimento de forragem e valor nutritivo de gramíneas anuais de estação fria submetidas a sombreamento por Pinus elliottii e ao sol pleno. Revista Brasileira de Zootecnia. vol.37 no.10 Viçosa Oct. 2008.

CASTRO, C.R.T.; CARVALHO, M.M. Florescimento de gramíneas forrageiras cultivadas sob luminosidade reduzida. Ciência Rural, v. 30, n. 1, 2000.

CASTRO, C.R.T.; GARCIA, R.; CARVALHO, M.M. et al. Efeitos do Sombreamento na Composição Mineral de Gramíneas Forrageiras Tropicais. Revista Brasileira de Zootecnia, 30(6S):1959-1968, 2001.

CASTRO, C.R.T.; GARCIA, R. Competição entre plantas com ênfase no recurso luz. Ciência Rural, Santa Maria, v.26,n.1,p, 167-194, 1996.

CASTRO, C.R.T.; PACIULLO, D.S.C. [2006] Boas práticas para a implantação de sistemas silvipastoris. Disponível em: www.cnpgl.embrapa.br/nova/publicacoes/comunicado/COT50.pdf Acesso em:23/03/2009.

CASTRO, C.R.T.; PACIULLO, D.S.C.; GOMIDE, C.A.M. et al. Dinâmica de perfilhamento de Brachiaria decumbens cv. Basiliski em sistema silvipastoril. 45a Reunião Anual da Sociedade Brasileira de Zootecnia, Lavras, MG -UFLA- 2008.

OLIVEIRA, T.K.D.; FURTADO, S.C.; ANDRADE, C.M.S et al. Sugestões para a implantação de sistemas silvipastoris. Embrapa Acre, 2003, 28p.

PACIULLO, D.S.C.; AROEIRA, L.J.M.; CARVALHO, M.M. Sistemas Silvipastoris na pecuária Leiteira. Embrapa Gado de Leite. Produção de leite a pasto: Técnicas de produção e de manejo da propriedade, p.63-84, 2009.

PACIULLO, D.S.C.; CAMPOS, N.R.; GOMIDE, C.A.M. et al. Crescimento de capim-braquiária influenciado pelo grau de sombreamento e pela estação do ano. Pesquisa agropecuária brasileira, Brasília, v.43, n.7, p.917-923, jul. 2008.

PACIULLO, D.S.C.; CASTRO, C.R.T. Sistemas silvipastoris na pecuária leiteira. Embrapa Gado de Leite, 2009.

PACIULLO, D.S.C.; CASTRO, C.R.T. Sistema silvipastoril e pastagem exclusiva de braquiária para recria de novilhas leiteiras: massa de forragem, qualidade do pasto, consumo e ganho de peso - Juiz de Fora : Embrapa Gado de Leite, 21 p. 2006.

PACIULLO, D. S. C.; CASTRO, C. R. T; ÁVILA PIRES, M. et al. Desempenho de novilhas leiteiras em pastagem solteira ou em sistema silvipastoril constituído por Eucalyptus grandis e leguminosas arbóreas. Congreso Nacional de Sistemas Silvopastoriles. Aspectos relacionados al componente forestal arbóreo, forestales. Argentina, 2009 
VALENTINI, P.V. e CASTRO, C.R.T. A importância do sistema silvipastoril na pecuária leiteira.

PUBVET, Londrina, V. 4, N. 7, Ed. 112, Art. 758, 2010.

PACIULLO, D.S.C.; DA SILVA, V.P.; CASTRO,C.R.T. et al. Sistemas Agrossilvipastoris na America do Sul: Desafios e potencialidades. Arranjos e modelos de sistemas silvipastois. Juiz de Fora: Embrapa Gado de Leite, 362p, p.13-50, 2007.

RIBASKI, J.; RAKOCEVIC, M.; RIBASKI, S.A.G. [2002] Sistemas silvipastoris como alternativas de desenvolvimento sustentável para regiões suscetíveis à degradação ambiental no sudoeste do estado do Rio Grande do Sul. Disponível em: <www.cnpf.embrapa.br/publica/folders/SistSilv01_2002.pdf>. Acesso em: 10/04/2009.

SARTOR, L.R.; MEZZALIRA.;SOARES, A.B. Produção de forrageiras hibernais em sistema silvipastoril.

Disponível em:www.cpact.embrapa.br/publicacoes/download/documentos/documento_166/PDFs/2/204.pdf Acessado em: 03/05/2009. 